\title{
Insurance Implications for Individuals with a High Risk of Breast and Ovarian Cancer in Europe
}

\author{
P.J. Morrison ${ }^{1, \#, ~ C . M . ~ S t e e l ~}{ }^{2}$, H.F.A. Vasen ${ }^{3}$, \\ D. Eccles ${ }^{4}$, D.G.R. Evans ${ }^{5}$, P. Møller ${ }^{6}$, \\ S. Hodgson ${ }^{7}$, D. Stoppa-Lyonnet ${ }^{8}$, J. Chang- \\ Claude $^{9}$, M. Caligo ${ }^{10}$, E. Olah ${ }^{11}$, \\ N.E. Haites ${ }^{12}$ and N.C. Nevin ${ }^{1}$ \\ ${ }^{1}$ Northern Ireland Regional Medical \\ Genetics Centre, Belfast City Hospital Trust, \\ Belfast, BT9 7AB, UK \\ ${ }^{2}$ School of Biomedical Sciences, University of \\ St. Andrews, Scotland, UK \\ ${ }^{3}$ Foundation for the Detection of Hereditary \\ Tumours, c/o University Hospital, \\ Rijnsburgerweg 10, 2333 AA Leiden, The \\ Netherlands \\ ${ }^{4}$ Department of Human Genetics, Princess \\ Ann Hospital, Southampton SO16 5YA, UK \\ ${ }^{5}$ Department of Medical Genetics, St Mary's \\ Hospital, Manchester, UK \\ ${ }^{6}$ Unit of Medical Genetics, The Norwegian \\ radium Hospital, N-0310 Oslo, Norway \\ ${ }^{7}$ Division of Medical and Molecular \\ Genetics, Guy's Hospital, London Bridge, \\ London SE1 9RT, UK \\ ${ }^{8}$ Unité de Génétique Oncologique Institut \\ Curie - Section Médicale 26, rue d'Ulm \\ 75231 Paris Cedex 05 France \\ ${ }^{9}$ Division of Epidemiology, German Cancer \\ Research Centre, Im Neuenheimer Feld 280, \\ D-69120 Heidelberg, Germany \\ ${ }^{10}$ Institute of Pathology, University of Pisa, \\ via Roma, 57,56126 Pisa, Italy
}

\footnotetext{
\# Correspondence: Dr. P.J. Morrison, Northern Ireland Regional Medical Genetics Centre, Belfast City Hospital Trust, Belfast BT9 7AB, UK, Tel: +44 1232329241 Ext. 2764, Fax: +44 1232 236911, E-mail: p.morrison@cableol.co.uk
}

\author{
${ }^{11}$ Department of Molecular Biology, National \\ Institute of Oncology, H-1525 Budapest, \\ Hungary \\ ${ }^{12}$ Department of Medicine and Therapeutics \\ (Medical Genetics), University of Aberdeen, \\ Foresterhill, Aberdeen, AB25 2ZD, UK
}

KEYWORDS: Insurance, genetic testing, Europe, guidelines, breast \& ovarian cancer

\section{BACKGROUND/INTRODUCTION}

In 1935, R.A. Fisher predicted the use of genetic information in assessing insurance risks [1]. Several genetic tests are now available routinely. Most genetic tests likely to be utilised by insurers are for later onset conditions, such as cancer, and neurological disease. Huntington disease (HD), an autosomal dominant disorder, has been a model for this type of testing. Several ethical and legal problems already have been recognised [2,3]. In 1995, the American Society of Human Genetics published a statement to help understanding of insurance issues [4]. Clearly, there is a difference between more highly penetrant autosomal dominant diseases such as HD, and such diseases as breast cancers. Life tables and penetrance have been worked out for $\mathrm{HD}$ and it is possible to predict the age of death within a narrow range. Cancers due to single genes such as breast cancer, which constitute only $5-10 \%$ of a predominantly non familial common cancer, present more difficulty, as accurate lifetime risk tables are unavailable or are difficult to compile with penetrance data of limited accuracy. In polygenic diseases such as Alzheimer disease and diabetes, gene markers 
may suggest a likely cause of death but not a specific lifetime prediction. Experience with non 'genetic' conditions, such as AIDS are also relevant, as homozygous carriers of the CCR5-32 AIDS allele show nearly complete resistance to HIV infection [5].

Several European countries have no legislation or guidelines on insurance and genetic testing. Countries that have some guidelines, have a moratorium on the use of genetic tests. For example, in France, the moratorium is up to five years, whilst in the Netherlands, it has been extended indefinitely. Once a moratorium has been introduced, it is difficult to find sufficient scientific evidence to justify lifting a ban on the use of genetic testing in underwriting practice [6].

\section{Definition of a genetic test}

A genetic test has been defined as "an examination of the chromosome, DNA or RNA to find out if there is an otherwise undetectable disease related genotype, which may indicate an increased chance of that individual developing a specific disease in the future" [7].

The UK advisory committee on genetic testing (ACGT) [8] defines it as "a test to detect the presence or absence of, or change in, a particular gene or chromosome".

\section{What percentage of policies are affected?}

In the UK, 95-97\% of life insurance policies are accepted at no increased premium. Only

1. Insurance companies will not insist on genetic tests.

2. Genetic test results will only affect insurance if they show a clearly increased risk of illness or death. A low increase in risk will not necessarily affect the premium.

3. Insurance companies will always seek expert medical advice when assessing the impact of genetic test results on insurance.

4. Insurers may take account of a test result only when reliability and relevance have been established.

5. Applicants for insurance will not be asked to take a genetic test, but existing test results should be given to the insurance company when it asks a relevant question, unless it has said this information is not required.

6. Existing genetic test results need not be disclosed in applications for life insurance up to $£ 100,000$ which are directly linked to a new mortgage for the purchase of a house to be occupied by the applicant(s).

7. An applicant will not be required to disclose the result of a genetic test undertaken by another person (such as a blood relative), and one person's test information will not affect another person's application.

8. The reason for an increased premium or rejection of an insurance application will be provided to the applicant's doctor on request.

9. Insurers will not "cherry pick" by offering a "preferred life" lower than normal premiums on the basis of their genetic test results.

10. An independent adjudication tribunal is being set up to consider complaints, which are unresolved.

11. Each year chief executives will need to demonstrate how they have complied with the code.

Fig. 1. Association of British Insurers principles for genetic testing. 
about $1 \%$ are declined, and $2-4 \%$ are rated up $[9,10]$. There is no analysis of these figures for specific diseases. The main reason for refusal or 'loaded' premiums is the above average sum assured, and not the type of 'high risk' individual assessed. Risks for insurers will be small if the policy value is low [10], for example under $£ 100,000$.

\section{THE UK EXPERIENCE}

In the UK, insurance recommendations are interesting because it is the only country in Europe to have had a recent change in insurance recommendations. These changes have been driven mainly by insurance companies. This contrasts with the Netherlands and other EU countries which have legislation generated by the government.

An Association of British Insurers (ABI) code of practice for genetic testing, [7] came into effect in January 1998. The code has several important features (Figure 1) and applies to all insurance, including life, permanent health, critical illness, long term care and medical expenses. Most 'relevant' UK insurance is predominantly life insurance linked to personal pensions, and property insurance [mortgage cover]. As the UK National Health Service provides free health care, health insurance is less frequently purchased than in the USA, although there has been a recent increase in sales of personal health insurance cover policies. The situation differs from the USA insurance market, which is dominated by private health insurance.

\section{The role of the Human Genetics Advisory Commission in the UK}

The Human Genetics Advisory Commission (HGAC), was established in December 1996 as a non-statutory advisory body to report to the government on various developments in genetics. The first HGAC report was published in

\footnotetext{
1. A permanent ban on the use of genetic testing is not appropriate. Recommendation is for introduction of a moratorium on genetic testing for at least 2 years.

2. There is not sufficient predictive ability of genetic tests at the moment to allow accurate risk assessment.

3. The life insurance industry could currently withstand limited adverse selection if non-disclosure of test results was current policy.

4. There is a perception of unacceptable discrimination - this may deter testing that may lead to beneficial treatment.

5. Arrangements for confidentiality of data are adequate under current practice.

6. No company should require taking of a test as a prerequisite of obtaining cover.

7. Increased research and collaboration between industry and science is required to improve knowledge of actuarial implications of genetic factors.

8. There should be a robust appeals procedure as part of any new system.

9. Recommendations are primarily relating to life insurance but the principles above should apply to other types of health insurance.
}

Fig. 2. Recommendations on genetic testing \& insurance of the Human Genetics Advisory Commission of the UK. 
December 1997 [11]. The commission has 10 members who include representation from clinical geneticists, the pharmaceutical industry, media, patient support groups, legal and lay persons. It also includes the chairman of the gene therapy advisory committee (GTAC), and of the Advisory committee on genetic testing (ACGT). The report recommended a two-year moratorium on genetic testing. Its conclusions are shown in Figure 2. The Association of British Insurers (ABI), also reported their recommendations at the same time as the HGAC.

\section{How have the recommendations been received?}

The Government press release stated that "People who have taken a genetic test can be confident that they will get fair treatment from insurers". The ABI in their news release [7] stated that "The insurance industry is very supportive of what the Government is trying to achieve...". The Sunday Times (London) of the $8^{\text {th }}$ November 1998, stated "DTI code leaves insurers free to create 'genetic underclass'". The Government plans to use a newly formed genetics insurance advisory committee (GIAC), [12] to validate genetic tests proposed by the ABI $[13,14]$. Already the ABI has produced matrices of autosomal dominant, autosomal recessive and $\mathrm{X}$-linked recessive diseases for potential validation. The list includes Huntington disease, multiple endocrine neoplasia (MEN-2), breast cancer (BRCA1 \& 2 genes), familial adeno-matous polyposis coli (FAP), Alzheimer disease, hereditary motor and sensory neuropathy (HMSN) and myotonic dystrophy. The UK has therefore become the first country in Europe in which regulations for genetic testing in the context of insurance are being shaped by the industry, even though the GIAC will have a role in validating the tests proposed by the ABI. How this relationship will work out in practice remains to be seen, and may require extension of existing discrimination laws to include those at risk of a genetic disorder or the introduction of entirely new legislation.

\section{THE BROADER EUROPEAN EXPERIENCE}

There is a plethora of measures in other European countries. In the Netherlands, it is considered that strict regulation will be needed. In 1995, a 5-year moratorium was extended indefinitely and insurers have agreed not to use genetic tests or existing genetic information for policies below NLG 300,000. Individual responsibility is seen as being extremely important. Limitations on the collection and use of genetic information are derived from the medical treatment and medical checks acts.

In Austria, the 1994 gene technology law states that employers and insurers are forbidden to obtain, request accept or use results of genetic analyses.

In Belgium, a 1992 Non-marine insurance law allows medical examinations etc. to be based only on past medical history establishing the applicant's medical state, and not on genetic analysis techniques capable of determining future state of health.

In France, the 1994 French Federation of Insurance Companies (FFSA) issued a statement saying that for 5 years, the FFSA will not use genetic information when determining applicants' insurability, even if favourable information is brought by applicants.

In Norway, a 1994 biotechnology law allows strict use of genetic tests. It states that it is 'forbidden to request, receive, retain or make use of genetic information from a genetic test result, and it is forbidden to ascertain if a genetic test has been performed'. This may not apply to diagnostic tests.

In 1997, Poland introduced a law, which established a general inspectorate for personal data protection. The German insurance system does not use genetic information to reach decisions about awarding coverage. There is no legislation in Hungary, Ireland, Italy, Portugal or Spain.

There is little doubt that most members of the European Union will have legislation in relation to the use of genetic information in the near future. Following the national referendum in 
Switzerland in June 1998, to limit genetic experimentation, in which the vote went against the proposal, there are no plans to introduce genetic legislation for the time being.

\section{LEGISLATION ON GENETIC TESTING IN OTHER COUNTRIES}

Australia had draft guidelines in July 1997, and these are currently being revised. Canada has no legislation. New Zealand issued guidelines in April 1997 on insurance and genetic tests. The situation in the USA is covered partly by the Discrimination act, 1996. Current bills passing through the US government include one on genetic information \& non-discrimination in health insurance $[15,16]$.

\section{Genetic testing in established cancer genetics disorders allows prevention}

Genetic tests have been used in the diagnosis and management of cancer for several years [17, 18]. For example, in multiple endocrine neoplasia type 2A (MEN2A), familial medullary thyroid cancer can result in early death by metastatic spread, presymptomatic testing has led to prophylactic thyroidectomy in high risk individuals in families in which a MEN2A gene mutation has been identified. Some clinicians have used DNA testing alone without the use of other investigations in such families [19]. Several children under the age of 10 years have been identified as carriers, with pathological confirmation of focal carcinoma. Thyroidectomy is "curative", however, such results are not easily extrapolated to later onset breast or colon cancers. There is a danger that patients may be reluctant to undergo genetic testing if insurance companies penalise gene carriers, rather than encouraging them to prolong their life expectancy by prophylactic surgery [20]. Ethical and legal implications may be an added difficulty. The duty to warn under law has been raised [21] Already one physician has been sued by the child of an affected MEN2A patient because she was not informed that the condition was hereditary [22]. Several European countries are developing guidelines for screening of breast cancer gene carriers and for the organisation of cancer genetic clinics [23].

\section{Benefits of genetic testing}

The finding of negative test results (i.e. nongene carriers) has been used to lower already high premiums, as in Austria [24]. However, as in the UK, insurance companies cannot insist that applicants should have genetic tests. Many individuals at risk and on a higher premium, will organise genetic tests at their own expense. Confirmation by genetic testing of a disease, such as Friedreich ataxia or HD does not increase the existing premium, but a negative test result has led to a reduced premium for some applicants.

Some insurers consider that genetic information is not essential for underwriting life insurance, and are not requesting information about genetic tests. Most applicants who were requested to provide further information were not rated at a higher premium or rejected. Some companies consider they can absorb this small extra load - only 1 in 20 policies are actually claimed on death, which is not an excessive amount.

\section{Over the counter genetic tests}

There has not been a large demand for commercial genetic testing in the UK. Over the counter testing is regulated by the ACGT, $[8,25]$. In the UK, it is considered that genetic testing services should be provided within the NHS [25]. It is important that the interpretation of genetic tests should be provided by an expert such as a clinical geneticist or other physician.

\section{The potential for discrimination}

Discrimination is an increasing problem, especially in employment. The Council of Europe's Convention on Human Rights and Biomedicine states that "Any form of discrimination against a person on grounds of his or her genetic heritage is prohibited". In the UK, 
applicants for training for military aircrews are biochemically screened for sickle cell disease and sickle cell trait. This approach is designed to protect the individual from the potentially catastrophic effects of sickling provoked by low oxygen pressures in flight. In the USA, it is not a bar to air crew training. Is this the thin end of the wedge? In EU countries, legislation is limited to broad statements. Our survey of European genetic centres involved in breast cancer testing showed that all the UK centres surveyed had had patients who refused testing because of fear of penalty or being unable to obtain insurance. Some $25 \%$ of UK centres had experience of patients who refused genetic testing because of fear of employment discrimination [26]. Most of the non-UK centres did not appear to have any major discrimination problems. This finding supports the HGAC statement that "there is a perception of unacceptable discrimination in the UK" [12]. The UK does have legislation on discrimination. The 'disability discrimination act 1995' deals with this issue and may conflict with some of the ABI guidelines, as it forbids employers discriminating against those who are disabled. However the definition of disabled does not cover asymptomatic individuals with a predisposition to genetic illness. 'Fair' discrimination is allowed in relation to insurance, i.e. discrimination is justified as long as it is supported with actuarial evidence. Thus, although it would be unlawful to refuse insurance, a premium commensurate with the risk would be allowed.

\section{The future}

The situation may change greatly with the patenting of genes by commercial companies. Already BRCA1 and BRCA2 gene tests have been patented by Myriad Genetics in the US, and if Myriad's European BRCA1 and BRCA2 patents are granted, costs of testing may increase and availability limited to certain European laboratories. Currently UK health insurance companies do not pay for or reimburse costs for genetic tests. Patents for hereditary non-polyposis cancer genes and the p16 melanoma gene are held by Human Genome Sciences and Sequana Therapeutics respectively [27]. Undoubtedly more patent granting is in the pipeline. Already, in the USA, it is difficult to obtain a BRCA1 \& BRCA2 test without paying $\$ 2400$ through a Myriad Genetics licensed laboratory. In the USA, several insurance companies will often reimburse the patient (albeit on the insurance companies testing terms).

At the moment, general public concern about the activities of insurance companies is limited. It appears that governments are not intervening with strict regulations. However, perhaps with the expansion of available genetic tests and more particularly, when genetic tests can more accurately predict susceptibility to multifactorial disease, the situation may change. Currently, insurance companies cannot insist on the disclosure of results of genetic tests or insist that patients undergo genetic testing. The stringent requirements for confidentiality and privacy need to be maintained by legislation as each one of us may carry some potentially 'abnormal' genes which in the future, may be more easily identifiable with completion of the human genome project.

\section{Acknowledgements}

This work was supported by a Biomed demonstration project grant number BMH4CT96-1133.

\section{References}

[1] Fisher, R.A. Linkage studies and the prognosis of hereditary ailments. International congress of Life Assurance Medicine, London, 1935: 1-3. Cited in Harper PS, Genetic testing and insurance. J. Royal Coll. Phys. Lond. 26, (1992) 184-187.

[2] Huggins, M., Bloch, M., Kanani, S. et al. Ethical and legal dilemmas arising during predictive testing for adult-onset disease: the experience of Huntington disease. Am. J. Hum. Genet. 47, (1990) 4-12. 
[3] Harper, P.S. Insurance and genetic testing. Lancet 341, (1993) 224-227.

[4] The Ad Hoc committee on genetic testing/insurance issues. Background statement. Genetic testing and Insurance. Am. J. Hum. Genet. 56, (1995) 327-331.

[5] Stephens, J.C., Reich, D.E., Goldstein, D.B., Doo-Shin, H., Smith, M.W., Carrington, M. et al. Dating the Origin of the CCR5-32 AIDSresistance allele by the coalescence of Haplotypes. Am. J. Hum. Genet. 62, (1998) 1507-1515.

[6] Morrison, P.J. Genetic testing and Insurance in the UK. Clin. Genet. 54, (1998) 375-379.

[7] Genetic testing ABI code of practice. Association of British Insurers, London UK. December 1997.

[8] Code of practice and guidance on Human genetic testing services supplied direct to the public. Advisory Committee on Genetic Testing. London, UK. September 1997.

[9] MacDonald, A.S. How will improved forecasts of individual lifetimes affect underwriting? Phil. Trans. R. Soc. Lond. B352, (1997) 1067-1075.

[10] LeGrys, J. Actuarial considerations on genetic testing. Phil. Trans. R. Soc. Lond. B352, (1997) 1057-1061.

[11] The implications of genetic testing for insurance. Human Genetics Advisory Commission. London, UK. December 1997.

[12] The Advisory and regulatory framework for biotechnology: report from the Government's review. Cabinet Office, and Office of Science and Technology. London UK. May 1999.

[13] Morrison, P.J. Implications of genetic testing for insurance in the UK. Lancet 352, (1998) 16471648.

[14] Government response to the Human Genetics Advisory Commission's report on the implications of genetic testing for insurance. Department of Trade and Industry Office of Technology, and the Department of Health, London, UK. November 1998.

[15] Rothenberg, K., Fuller, B., Rothstein, M., Duster, T., Ellis Kahn, M.J., Cunningham, R. et al. Genetic information and the workplace: legislative approaches and policy challenges. Science 275, (1997) 1755-1757.

[16] Wadman, M. Privacy bill under fire from researchers. Nature 392, (1998) 6.
[17] Morrison, P.J., Hadden, D.R., Hughes, A.E., Kennedy, L., Russell, C.F.J. and Nevin, N.C. Gene probe analysis in an informative family with multiple endocrine neoplasia syndrome type 2A (MEN2A) improvement in carrier risk estimation. Q. J. Med. 80, (1991) 597-603.

[18] Groden, J., Thliveris, A., Samowitz, W., Carlson, M., Gelbert, L., Albertsen, H. et al. Identification and characterization of the familial adenomatous polyposis coli gene. Cell 66, (1991) 589-600.

[19] McNally, D., Campbell, W.J., Sloan, J.M., Morrison, P.J. and Russell, C.F.J. Thyroidectomy for medullary carcinoma in MEN 2A: positive genetic screening as the sole indicator for surgery. U. Med. J. 66, (1997) 134-35.

[20] Rodrigurez-Bigas, M.A., Vasen, H.F.A., O’Malley, L., Rosenblatt, M.T., Farrell, C., Weber, T.K. and Petrelli, N.J. Health, life and disability insurance and hereditary non-polyposis colorectal cancer. Am. J. Hum. Genet. 62, (1998) 736-737.

[21] The American Society of Human Genetics social issues subcommittee on familial disclosure. ASHG statement: Professional disclosure of familial genetic information. Am. J. Hum. Genet. 62, (1998) 474-483.

[22] Rothenberg, K.H. Breast cancer, the genetic "Quick fix" and the Jewish community. Health Matrix 7, (1997) 97-124.

[23] Vasen, H.F.A., Haites, N.E., Evans, D.G.R., Steel, C.M., Møller, P., Hodgson, S., Eccles, D., Morrison, P., Stoppa-Lyonnet, D., Chang-Claude, J. and Caligo, M. Current policies for surveillance and management in women at risk of breast and ovarian cancer: a survey among 16 European family cancer clinics. Eur. J. Cancer 34, (1998) 1922-1926.

[24] Hauser, G. and Jenisch, A. Laws regarding insurance companies. J. Med. Genet. 35, (1998) 526-528.

[25] Report on genetic testing for late onset disorders. Advisory Committee on Genetic Testing. London, UK. September 1998.

[26] Morrison, P.J., Steel, C.M. and Nevin, N.C. Regulation of insurance \& genetic testing in the UK \& other European countries. Am. J. Hum. Genet. 63(Suppl), (1998) A12.

[27] Editorial. Capitalizing on the genome. Nat. Genet. 13, (1996) 1-3. 


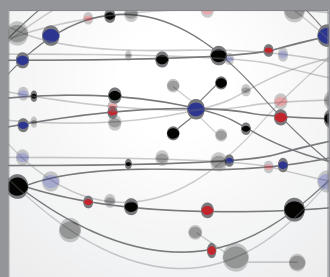

The Scientific World Journal
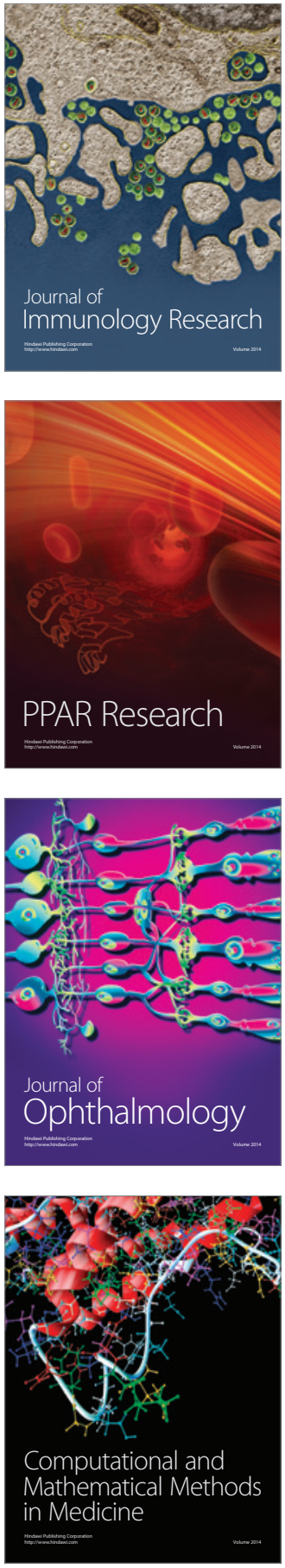

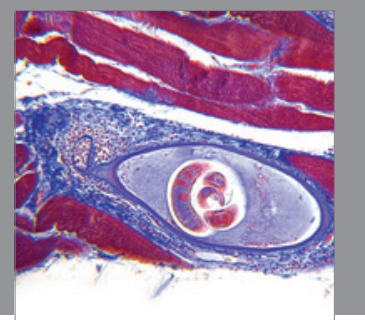

Gastroenterology

Research and Practice
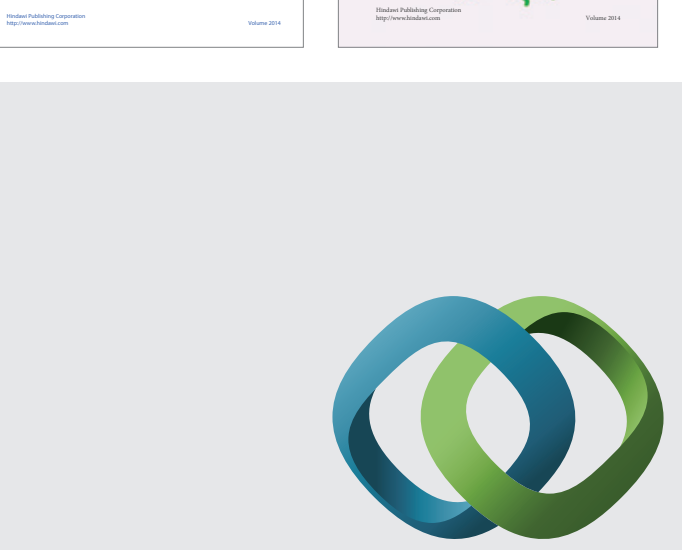

\section{Hindawi}

Submit your manuscripts at

http://www.hindawi.com
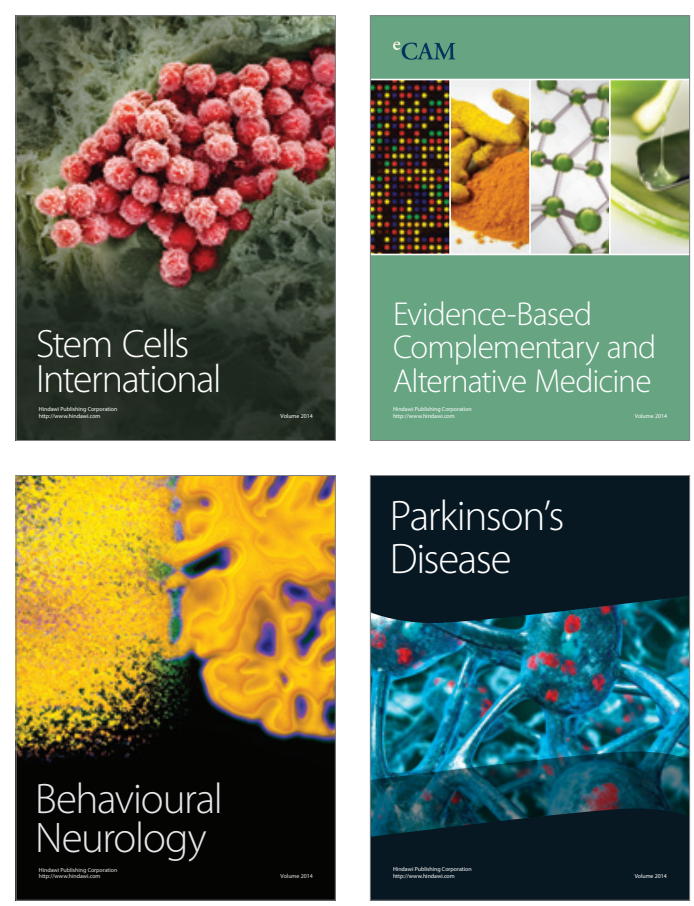

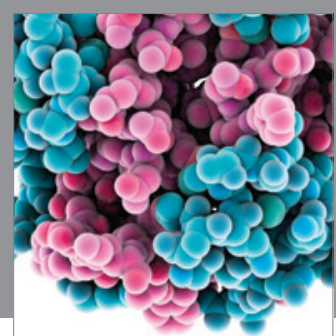

Journal of
Diabetes Research

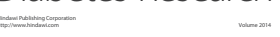

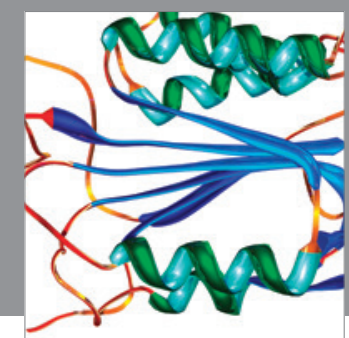

Disease Markers
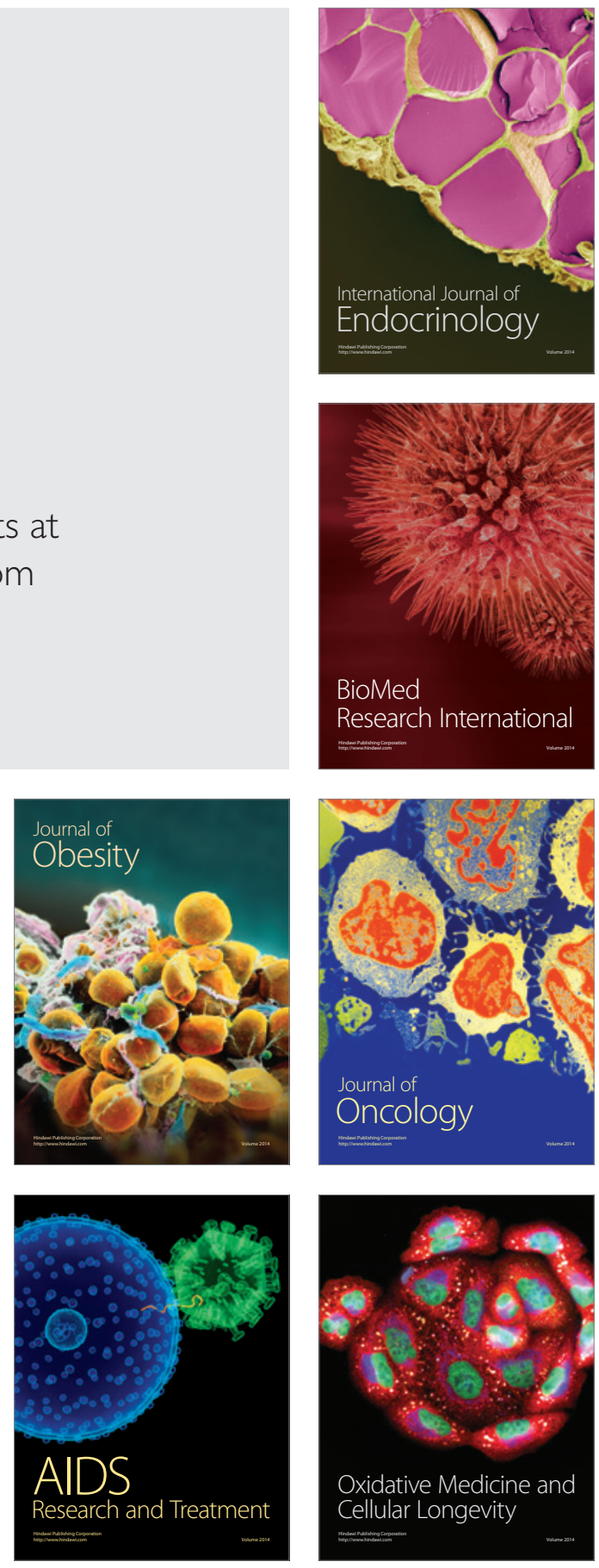